\title{
An unusual mass in the thigh
}

\author{
K H Siddiqui, J G H Hubbard
}

A 79-year-old woman presented with several weeks history of a slowly enlarging painful mass in the upper part of her left thigh. She had a history of panproctocolectomy, performed 12 months earlier for longstanding ulcerative colitis and synchronous carcinomas of the sigmoid colon (Dukes B) and mid rectum (Dukes C). Pre-operative investigations and peroperative inspection showed no evidence of overt metastasis. Examination revealed a $10 \times 5 \mathrm{~cm}$ firm, non-tender mass in the thigh fixed to the muscles. The rest of the examination was otherwise unremarkable. The magnetic resonance imaging (MRI) scans are shown in the figure.

Department of

Victoria Infirmary,

Newcastle upon Tyne,

UK

K H Siddiqui

J G H Hubbard

\section{Correspondence to}

Mr JGH Hubbard,

Department of General

Surgery, Sunderland Royal

Hospital, Kayll Road,

Sunderland SR4 7TP, UK

Accepted 13 May 1998

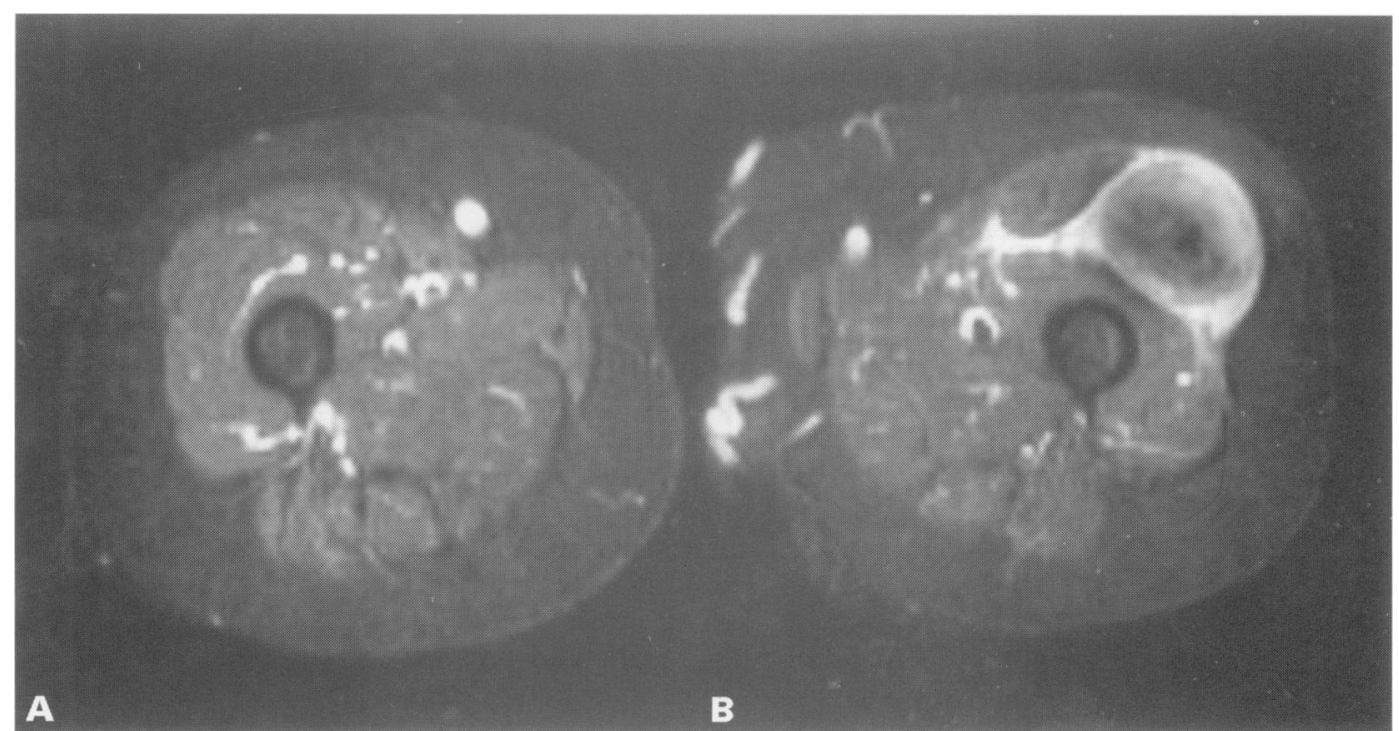

Figure MRI scans of (A) normal right thigh, (B) left thigh

\section{Questions}

1 What abnormality is seen on MRI ?

2 What is the likely diagnosis ?

3 What are the more likely sites for this abnormality to develop ? 


\section{Answers}

QUESTION 1

MRI shows a large tumour, which appears to be encapsulated, occupying the left vastus lateralis muscle. An enlarged lymph node was also noted (on other views) in the ipsilateral groin.

\section{QUESTION 2}

Fine needle aspiration cytology of the lesion confirmed the presence of adenocarcinoma, compatible with a large bowel primary. Carcinoembryonic antigen was also elevated to 202 $\mu \mathrm{g} / 1$.

\section{QUESTION 3}

The sites of first recurrence of colorectal carcinoma ${ }^{1}$ are liver ( $\left.>30 \%\right)$, lungs and locoregional disease (20-25\%), other intra-abdominal sites (15-20\%) and other extra-abdominal sites $(10 \%)$ including bone, lymph nodes, brain and skin. ${ }^{2}$ Skeletal muscle is an unusual site of colorectal cancer metastasis.

\section{Discussion}

The case described above was treated initially with radiotherapy (with a view to later surgical excision). This provided a good symptomatic response and some reduction in tumour size, however, our patient soon developed widespread subcutaneous metastasis over the chest wall and liver metastasis, and died 6 months after her initial presentation.

Skeletal muscle is an unusual site of colorectal cancer metastasis and only a few cases have been reported. ${ }^{3-6}$ Skeletal muscle makes up $40-50 \%$ of total body weight and receives a relatively large blood flow for its metabolic rate. As tumour cells have been detected in the peripheral blood of up to $50 \%$ of the patients

1 Turk PS, Wanebo HJ. Results of surgical treatment of nonhepatic recurrence of colorectal carcinoma. Cancer 1993;71 (12 suppl):4267-7.

2 Willett CG, Tepper JE, Cohen AM, Orlow E, Welch CE Willett CG, Tepper JE, Cohen AM, Orlow E, Welch CE. Failure patterns following curative rese
cinoma. Ann Surg 1984;200:685-90.

3 Laurence AE, Murray AJ. Metastasis in skeletal muscle sec3 Laurence AE, Murray AJ. Metastasis in skeletal muscle secBr $\mathcal{F}$ Surg 1970;57:529-30.

4 Torosian MH, Botet JF, Paglia M. Colon carcinoma metastatic to thigh - an unusual site of metastasis, report of a case. Dis Colon Rectum 1978;30:805-8.

\section{Learning points}

- muscle metastasis from colorectal cancer is rare

- pain and swelling are presenting features

- direct questioning regarding skeletal muscle should be carried out at patient review and, if symptomatic, examination should be performed

- in the absence of other evidence of metastatic spread, resection may improve the prognosis

undergoing colonic resection, ${ }^{7}$ it is perhaps surprising that skeletal muscle is infrequently involved as a site of metastatic disease. The neovascularisation of tumours may occur because of their ability to produce lactic acid and mimic the effects of anoxia. It has been suggested that the conditioning of blood vessels within skeletal muscle to lactic acid may be responsible for its resistance to metastatic spread. $^{8}$

It has been hypothesised that a solitary muscle metastasis may act as the source for further dissemination of disease, as in two cases ${ }^{36}$ proximal ipsilateral lymph node metastasis occurred following the appearance of a muscle metastasis, suggesting lymphatic spread from the muscle metastasis. Early complete excision in these cases may have improved the prognosis. In our case proximal ipsilateral lymph node involvement was present at diagnosis and was followed rapidly by generalised metastasis.

\section{Final diagnosis}

Colorectal cancer metastasis in the left thigh muscle.

Keywords: colorectal carcinoma; skeletal muscle metastasis

5 Lampenfield ME, Reiley MA, Fein MA, Zaloudek CJ Metastasis to skeletal muscle from colorectal carcinom case report. Clin Orthop 1990;256:193-6.

6 Araki K, Kobayashi M, Ogata T, Takuma K. Colorectal carcinoma metastatic to skeletal muscle. HepatoGastroenterology 1994;41:405-8.

7 Griffiths JD, McKinna JA, Rowbotham HD, Tsolakidis P, Salsbury AJ. Carcinoma of the colon and rectum: circulating malignant cells and five year survival. Cancer 1973;31:226-

8 Seely S, Possible reasons for the high resistance of muscle to cancer. Med Hypotheses 1980;6:133-7. 